\title{
Análise semiótica do clip de This is the new shit de Marilyn Manson
}

Daniel Levy CANDEIAS (mestrando FFLCH-USP)

RESUMO: Análise de um clipe de Marilyn Manson, baseada nos princípios teóricos de Greimas e da Semiótica Plástica, desenvolvida por Floch.

PALAVRAS-CHAVE: Semiótica; Videoclipe; Floch

\begin{abstract}
Analysis of a Marilyn Manson's videoclip, in conformity to the theoretical principles of Greimas and the Plastic Semiotic's developed by Floch.
\end{abstract}

KEYWORDS: Semiotic; videoclip; Floch 


\section{Introdução}

Em 5 de janeiro de 1969, nasce Brian Warner, que passa por infância conturbada, e inicia carreira de jornalista. Nessa época, faz alguns contatos e monta a banda "Marilyn Manson And The Spooky Kids". Marilyn Manson, seu pseudônimo, é a união de Marilyn Monroe e Charles Manson, composto do mesmo modo que os dos outros músicos: formados pela junção de nomes de mulheres famosas e assassinos. Com o passar dos anos, o conjunto se reduz apenas ao nome Marilyn Manson, e por haver muita rotatividade de integrantes, o ex-Brian Warner é quase tomado como cantor solo. No princípio, abre shows, como os de Nine Inch Nails e Danzig. E aos poucos, vai se tornando um dos artistas mais conhecidos da música pop.

Podem ser depreendidos dois motivos para a formulação de "Marilyn Manson". O primeiro deles diz respeito à crítica ao mundo da fama, no qual pessoas tão diferentes recebem os mesmos tratamentos, por causa da mitologização que as esvazia de sentido. O segundo também referente a esse processo, agora, o assume, por meio de uma tentativa de abarcar a totalidade na junção de opostos. Afinal, podendo ser até interpretado como uma reformulação do "Sublime e grotesco", de Victor Hugo, a união de Charles Manson e Marilyn Monroe parece conciliar oposições fundamentais da cultura ocidental, como: o belo e o feio, o bom e o mau, o masculino e feminino. Desse modo, cria-se uma figura mítica, já que, como se sabe, essa última costuma realizar termos complexos e fundamentais. Como diz o próprio criador do mito: "Eu acho que Deus e o Diabo são apenas duas palavras, como Marilyn Manson".

Note-se, portanto, que no pseudônimo escolhido pelo artista, encontram-se a crítica à mitificação e sua assunção, constituindo o efeito de sentido da ironia, pois o que se afirma no enunciado é negado na enunciação. Isso está presente em grande parte de sua obra, que costuma se apropriar de figuras de outros discursos para lhes dar novos significados. O que quer dizer que, levando em conta a distinção feita por Maingueneau entre os discursos do jansenista e humanista devoto, num primeiro momento, é possível identificar o objeto de estudo desse trabalho com o segundo. Isso porque ao contrário de uma relação polêmica, o uso das figuras, e até mesmo de temas de outros discursos, parece revelar um contrato com a alteridade.

Mas do mesmo modo como se dá na escolha do pseudônimo, esse contrato coocorre com a polêmica, pois o uso de elementos de outros discursos provoca tal transformação de significado, que eles são subvertidos. Um exemplo é o nazismo que, associado pelo artista à indústria cultural, tem seus símbolos, que eram plenos de significado político-religioso, transmutados em meros logotipos, e seus uniformes, que davam determinado lugar social a indivíduos de patente, tratados como artigos de moda. Pode-se afirmar, por isso, que, muitas vezes, a contratualidade de seu discurso é na verdade uma polemização. $\mathrm{O}$ que se torna claro quando as figuras ou temas apropriados vão de encontro à ideologia do cantor. Ressalta-se, porém, que há casos, como as apropriações de elementos da obra de Magritte, do dadaísmo e do expressionismo, em que a ironia desaparece, havendo apenas uma intertextualidade contratual no enunciado, sem que haja polêmica na enunciação.

Para que se entenda melhor esse processo de geração de termos complexos, por meio do qual a ironia às vezes se apresenta, e às vezes, não, resta acrescentar algo sobre 
os valores ideológicos que podem ser depreendidos do enunciador. Acima de tudo, Marilyn Manson é um crítico da cultura, principalmente, no que diz respeito a aspectos da sociedade americana. Seus ataques mais frequientes dirigem-se à Política, Igreja, Moral e ao mundo pop. Veja-se o seguinte trecho da canção "In the shadow of the valley of the death" (Na sombra do vale da morte):

\begin{tabular}{|l|l|}
\hline Death is policeman & Morte é policial \\
Death is the priest & Morte é o padre \\
Death is the stereo & Morte é o aparelho de som \\
Death is a TV & Morte é uma TV \\
Death is the Tarot & Morte é o Tarot \\
Death is an angel and & Morte é um anjo e \\
Death is our God & Morte é nosso Deus \\
killing us all & Matando todos nós \\
\hline
\end{tabular}

A postura crítica é predominante em seu trabalho, contrapondo-se à ideologia do discurso oficial, na medida em que valoriza elementos como a tradição da arte desvinculada do pop, o sexo sem nenhum preconceito, a estética gótica e sadomasoquista. O que quer dizer que talvez seja pertinente a escolha da categoria semântica identidade x alteridade para seu enunciado geral (obras, entrevistas, etc...). No discurso do outro, o de Marilyn Manson é alteridade, e nos seu, os outros o são, sendo euforizados os objetos de valor que dizem respeito a ele como ator, a identidade, no seu universo. Nas suas próprias palavras:

"Fazer coisas estranhas, para mim, se tornou uma coisa muito comum, como ir ao shopping, ao cinema ou ao Mc Donald's".

Talvez seja a impossibilidade do roqueiro se desvincular totalmente da alteridade que o faça tonicizar ao máximo a identidade, ensejando a malícia enunciativa de assumir valores no enunciado, criticando-os na enunciação. Partindo do princípio de que sua música faz parte do ambiente cultural que lhe serve de crítica, sua imagem é construída como a de alguém que despreza a tal ponto o indivíduo que assume tais valores, que ele se torna até mesmo motivo de riso - e a imagem do outro é sempre utilizada para ser negada. Constituída desse modo, a enunciação pressupõe um enunciatário com essa mesma capacidade de complexificação de negação na afirmação, principalmente, porque o uso de figuras consagradas pela sociedade tem uma intensidade crítica tão forte (como é o caso de Cristo, Papa e Virgem Maria), e algo até blasfematório, que as pessoas que realmente se identificam com a ideologia vigente jamais aceitariam. O que exclui grande parte de possíveis más interpretações, com respeito às figuras ironizadas pelo cantor, e instaura uma polêmica explícita com as ideologias atacadas.

Essa é uma breve apresentação do discurso geral e do Ethos de Marilyn Manson, que serve de introdução a esse trabalho. Sua proposta é analisar, por meio da semiótica greimasiana, e portanto, tendo como base a discriminação dos níveis fundamental, narrativo e discursivo, do percurso gerativo de sentido, o clipe de "This is 
the new shit”, canção do álbum The golden age of grotesque. Para tanto, utiliza-se também a teoria da semiótica plástica de Floch, com a qual se determina a organização da imagem por meio das categorias topológicas, cromáticas e eidéticas, constando a possibilidade de efeito poético, com a averiguação da presença ou ausência de semisimbolismo. Sendo o videoclipe um objeto sincrético, ou seja, detentor de muitas semióticas diferentes, para uma análise esgotá-lo seria necessário um estudo sobre a música e as relações com a letra, e outro relacionando esse último com as imagens do plano da expressão. Mas por motivos de espaço, as análises restringem-se quase que somente à letra e às imagens.

\section{Análise da letra da música}

Abaixo, a letra da música com a tradução:

\begin{tabular}{|c|c|}
\hline This is the new shit & Esta é a nova merda \\
\hline Everything has been said before & Tudo já foi dito antes \\
\hline There's nothing left to say & Não há nada mais para se dizer \\
\hline anymore & Quando tudo isso é a mesma coisa \\
\hline When it's all the same & Você pode pedir isso pelo nome \\
\hline You can ask for it by name & \\
\hline & Murmúrio, Murmúrio, Vadia, Vadia \\
\hline Babble, Babble, Bitch, Bitch & Rebelde, Rebelde, Festa, Festa \\
\hline Rebel, Rebel, Party, Party & Sexo, Sexo, Sexo, não esqueça a \\
\hline Sex, sex, sex, don't forget the & violência \\
\hline violence & Blá, blá, blá \\
\hline Blah, blah, blah & Pegue seu amorzinho triste e sozinho \\
\hline Got your lovey-dovey sad and & Cole seu slogan estúpido \\
\hline lonely & Todo mundo canta junto \\
\hline Stick your stupid slogan in & \\
\hline Everybody sing along & $\begin{array}{l}\text { Seus filhos da puta, estão prontos para } \\
\text { a nova merda? }\end{array}$ \\
\hline $\begin{array}{l}\text { Are you motherfuckers ready for } \\
\text { the new shit? }\end{array}$ & $\begin{array}{l}\text { Levantem e admitam: o amanhã nunca } \\
\text { chegará }\end{array}$ \\
\hline Stand up and admit tomorrow's & Esta é a nova merda \\
\hline never coming & Levantem e admitam \\
\hline This is the new shit & A gente tem? NÃO! \\
\hline Stand up and admit & A gente quer? SIM! \\
\hline Do we get it? NO! & Esta é a nova merda \\
\hline Do we want it? YEAH! & Levantem e admitam \\
\hline This is the new shit & \\
\hline Stand up and admit & Agora é você-sabe-quem \\
\hline & Eu tenho o você-sabe-o-quê \\
\hline Now it's you-know-who & Eu enfio isso em você-sabe-onde \\
\hline I've got the you-know-what & Você sabe por quê, você não liga \\
\hline
\end{tabular}




\begin{tabular}{|l|l|}
\hline I stick it in the you-know-where & Agora é você-sabe-quem \\
You know why, you don't care & Eu tenho o você-sabe-o-quê \\
Now it's you-know-who & Eu enfio isso em você-sabe-onde \\
I've got the you-know-what & Você sabe por quê, você não liga \\
I stick it in the you-know-where & Agora é você-sabe-quem \\
You know why, you don't care & Eu tenho o você-sabe-o-quê \\
Now it's you-know-who & Eu colo isso em você-sabe-onde \\
I've got the you-know-what & Você sabe por quê, você não liga \\
I stick it in the you-know-where & Agora é você-sabe-quem \\
You know why, you don't care & Eu tenho o você-sabe-o-quê \\
Now it's you-know-who & Eu enfio isso em você-sabe-onde \\
I've got the you-know-what & Você sabe por quê, você não liga \\
I stick it in the you-know-where & \\
You know why, you don't care & Então, \\
So, & Deixe-nos entreter você \\
Let us entertain you & \\
\hline
\end{tabular}

A canção inicia com o seguinte argumento: tudo já foi dito, nada mais pode ser novo, e sendo tudo sempre igual, não há nada que já não seja reconhecido facilmente ("pedir as coisas pelo nome"). Na segunda estrofe, encontram-se reunidos temas e figuras recorrentes da cultura de massa, principalmente da música pop, e que podem ser considerados clichês. Segue a frase "Blá blá blá", que acentua o tom de cansaço pela repetição, e logo depois, a sugestão do que poderia ser chamado de "romantismo barato", "Pegue seu amorzinho...", dando prosseguimento à crítica. Termina, depois, com a estrofe, na qual se constata que tudo isso é aceito por todos: "todo mundo canta junto". Essa primeira parte refere-se à cultura, e em especial, à canção pop. Há um enunciador que aponta uma mesmice na produção dos cancionistas, sustentada pela aceitação do público. "Murmúrio... todo mundo canta junto" é uma fórmula e quase um receituário do sucesso. Note-se que essa última é uma espécie de reprodução do enunciado dos artistas que são alvo de crítica. Definindo-os como possíveis interlocutores, pode-se dizer que há, aqui, uma embreagem actancial, com a qual se neutraliza a diferença entre interlocutor e enunciador.

No trecho seguinte, parece que esse processo se acentua. Se é possível afirmar que, nele, há uma figurativização dessa mesmice, tratando-o como a fala do interlocutor criticado, também é possível fazê-lo com sua própria execução, por causa da embreagem, justamente no refrão, o qual corresponde ao ápice da música. Portanto, ao mesmo tempo que há uma crítica ao uso desses elementos, há também uma assunção. E quando se ouve que a música traz a "nova merda", a tensão aumenta, tornando-se mais clara, pois o refrão tem a mesma banalidade do objeto criticado, mas que por ser tão banal, e até grosseiro, revela um tom de ironia, assumindo a cultura pop no enunciado, e negando-a na enunciação - como está apresentado acima, processo constantemente utilizado por Marilyn Manson.

A parte que começa com "Agora é você-sabe-quem" e termina com "você não liga" reitera a execução da mesmice e a passividade do público, tratado aqui como 
"você". O enunciador responde a todas as perguntas básicas "Quem?”, "O que?", "Onde? (com sentido de direcionamento de ação "enfio em você-sabe-onde"), que resumem a forma básica da oração, sujeito - verbo - predicado, com expressões dêiticas. E desse modo, aponta como a mesmice é vazia e conhecida pelo enunciatário que faz parte dos consumidores. Excepcionalmente, o esquema narrativo dessa enunciação inclui a etapa da sanção, pois os enunciatários, os ouvintes, participam da música como atores, respondendo às perguntas, ocorrendo assim uma nova embreagem actancial, recorrente nos textos de propaganda, que mostram, no discurso, os receptores consumindo seus produtos. Isso talvez se dê para apontar o caráter propagandístico da cultura de massa, o qual se explicita na canção, por meio dos imperativos, e principalmente, do final, "Então, deixe-nos entreter você", que pode ser entendido como o auge da ironia, já que a argumentação anterior é uma depreciação do entretenimento.

Em poucas palavras, "This is the new shit" é um ataque à mesmice e até aos valores culturais vigentes, que se revelam nas figuras e temas de festa, violência, e assim por diante. Pensando assim, pode-se afirmar que, no nível fundamental, estabelece-se a categoria semântica identidade $\mathrm{x}$ alteridade, cujo primeiro termo, no nível narrativo, transforma-se no objeto de valor mesmice, constituindo o seguinte quadro semiótico:

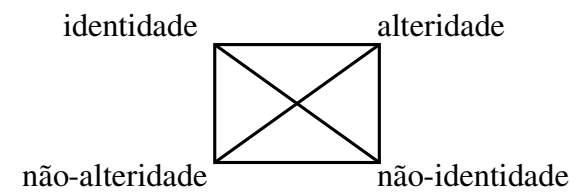

Tal categoria está homologada à de integração x transgressão. A assunção da mesmice (identidade) é equivalente à integração ao mundo pop e a transgressão, à sua crítica. Sob o efeito de ironia, quando há a euforização da identidade - também euforização da integração - no enunciado, na enunciação se dá o oposto.

No nível narrativo, consideram-se os sujeitos do ser tanto os artistas quanto o público, que podem entrar em conjunção com o objeto de valor mesmice. Os sujeitos do fazer, porém, limitam-se aos primeiros. O ator Marilyn Manson, destinador-julgador, julga que a produção artística vigente não é boa arte, porque se faz por meio de fórmulas, e critica-a, assumindo o papel de quem as produz. Desse modo, concretiza papéis actanciais paralelos: destinador que julga verdadeiro e falso, sujeito do ser que oscila entre conjunção e disjunção e entre euforia e disforia com a mesmice, sujeito do fazer que coloca o sujeito do ser em conjunção e disjunção com essa última, e sujeito da manipulação que estimula um querer-ser e um não-querer-ser.

\section{Análise da imagem}

No plano do conteúdo da imagem, há uma narrativa, que vai desde a chegada de Marilyn Manson ao local onde se realizará seu show, à passagem pelo camarim, para 
se preparar junto com os outros integrantes, e o show efetivamente realizado, do que se depreende o percurso narrativo de aquisição de competência e perfórmance. Como na canção, pode-se estabelecer a categoria semântica identidade $\mathrm{x}$ alteridade para o nível fundamental do videoclipe. E novamente no refrão, cantado no show, ocorre a figurativização da perfórmance e conjunção com a mesmice. Tem-se, portanto, o seguinte quadrado semiótico, cujo percurso disjunção $\rightarrow$ não-disjunção $\rightarrow$ conjunção aparece no texto:

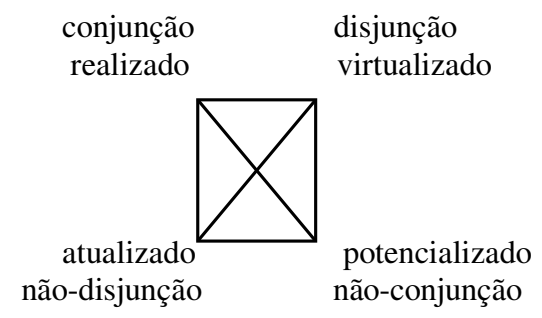

Do mesmo modo como é retratada a música pop, pode-se dizer que no videoclipe, a narratividade "pára" no tempo, pois são selecionadas cenas dos bastidores e do show, que se desenrolam concomitantemente. No início, Marilyn Manson aparece num carro com três mulheres (uma é a motorista), e chega a um local, o qual, se deduz depois, se trata do lugar do show. Há algumas cenas curtas do camarim e uma do público aguardando, sendo que a primeira dura mais. O líder da banda sai do carro e, acompanhado de duas das mulheres, canta a primeira parte da música, instaurando a cena, na qual o artista se dirige a si mesmo. A canção continua ("Murmúrio..."), dessa vez, já no camarim, onde todos os integrantes da banda se aprontam, bajulados e ajudados por mulheres nos mesmos trajes sensuais que as do começo. Aqui, surge uma nova instância cênica: o roqueiro aparece cantando diretamente para a câmera, ocupando posição central, tendo como fundo a parede de alguma região do local do show. Deduz-se que essa seria a instalação do "ator" do clipe, porque a disposição da imagem é muito semelhante ao padrão de cenas "neutras", em que o artista simplesmente canta para o telespectador.

Novamente, configuram-se três atores: o do camarim (artista para artista ou para si/não-alteridade, porque seu discurso trata o mundo pop como outro), o do show (artista para o público/identidade) e o do clipe (Marilyn Manson para o telespectador/identidade, porque também coloca o público em conjunção com a mesmice). A partir dessas três cenas, estabelece-se, no plano da expressão, as categorias cronológicas de anterioridade $\mathrm{x}$ posterioridade e a cinética, que, tensivamente, por meio da categoria longo $\mathrm{x}$ breve, ajuda na análise das relações entre as durações dos elementos analisados.

Desse modo, é possível fazer duas observações sobre a organização temporal do videoclipe. A primeira delas é a de que a ordem de suas partes principais, divididas nas três cenas descritas acima - camarim/chegada, show e clipe, denominadas, 
respectivamente como A, B e C -, é a seguinte: A / B / A / B / A / C / A / C / A / C / (Início do 1. refrão) B / C / B/ (fim) A / B / C / B / A / C / A / C (início do 2. refrão) / B / C / B / C... (fim) (início de "Agora, você sabe...) B/C... / A / C / B / (fim) A / B / A / B / A / C / B / A / B / A / B / C (início do 3. refrão) B (fim) (Deixe-nos...) A / B / C/ A / B / A / B... A segunda é a de que, no início, a parte A tem mais duração, perdendo depois bastante espaço para B e um pouco para C. Mais adiante, C e B predominam. Ao final, C desaparece, e há quase a mesma duração entre as outras duas. Assim, pode-se afirmar, que há uma intercalação entre competência e perfórmance, considerando a instância do clipe e do show como perfórmances, e a do camarim e chegada como competência.

Essa última ocupa mais tempo no início. As cenas do camarim e da chegada duram mais e não dão muito espaço às outras, em principal, à do show. A partir do primeiro refrão, a situação se reverte, fazendo com que a perfórmance ganhe mais projeção, cedendo uma parte do tempo à competência, quando a música retorna ao seu início (mas sempre menos do que anteriormente). Pode-se dizer que relação entre as duas instâncias vai se igualando, porque a música está terminando, a cena do camarim é dúbia, mas parece ser de depois do show, e a parte do início da canção se mistura com a que diz "Então, deixe-nos entreter você", a qual pode ser interpretada como aquisição de competência, porque aponta para uma nova perfórmance.

Depreende-se, portanto, uma relação semi-simbólica entre categorias do nível narrativo e do plano da expressão visual: quando a perfórmance tem mais intensidade, sua cena é mais longa, quando tem menor, mais breve, e o mesmo se dá com a competência. Essa relação se estabelece também com o conteúdo da letra. Prova disso é que o ápice da perfórmance se dá no momento do refrão, que o clipe acompanha com as cenas do show efetivamente realizado.

A cor também tem papel fundamental na organização dessas cenas, pois o ator do clipe aparece em frente a um fundo de tom esverdeado, e sob luz desse mesmo tom, o do show, aparece sob luz de tom azul (cor fria) e o dos bastidores, num cenário onde, no princípio, há, predominantemente, tons azuis, verdes, acinzentados (cores frias), mas aos poucos com as mulheres e a passagem para o camarim, compreende o vermelho, amarelo (cores quentes), e muitas outras. Se se lembrar que os atores do clipe e o do show são os que euforizam a identidade e que o dos bastidores é o que complexifica a foria da identidade e da alteridade, constitui-se o seguinte quadrado semiótico, representante da relação semi-simbólica, baseado no que se euforiza:

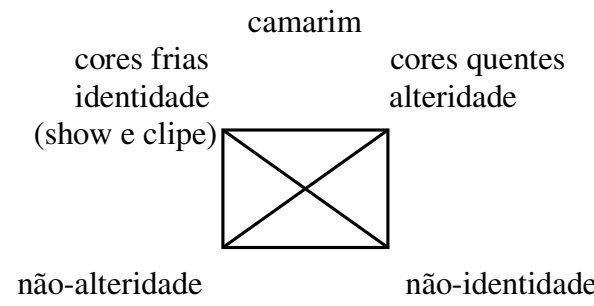

cores neutras 
Há como associar também os dois semi-simbolismos, relacionando as cores frias e a euforização da identidade com a perfórmance, e o complexo cores quentes/frias, euforia x disforia, com a competência. (Como na letra da canção, essa relação patêmica é depreendida dos atores, banda e público. O efeito de ironia pressupõe um enunciador que nega os valores ligados à identidade e afirma os de alteridade).

Ainda no plano do conteúdo, alguns detalhes precisam ser ressaltados.

O local do show, cujo exterior aparece no início do filme, é chamado de Reichsparteitagsgelände, lugar onde se davam desfiles e encontros do partido nazista alemão na época de Hitler. O logo de Marilyn Manson, o qual se vê nos dois púlpitos do palco, é inspirado no símbolo da SS (Schutzstaffeln), a polícia nazista. Abstraindo a moldura do primeiro, que lhe é tão opcional como para o outro, há um aglomerado de faixas brancas, que não são tão iguais por se tratarem de letras diferentes, as iniciais do que ou quem representam, intercaladas pelo preto do fundo. Veja-se os dois abaixo (o da direita é o da SS e o da esquerda, do roqueiro):
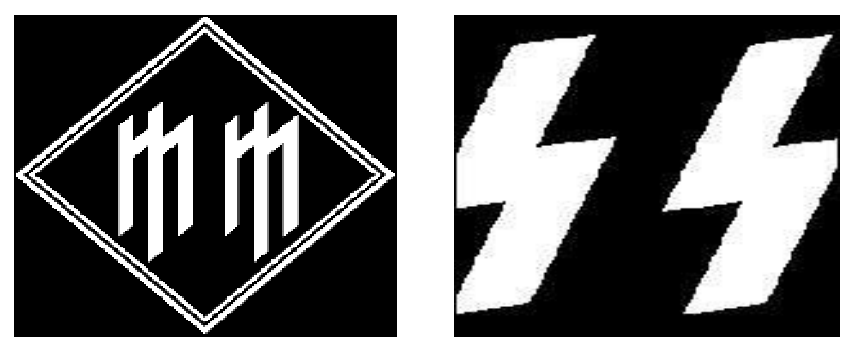

A relação entre o nazismo e a cultura de massa já está apontada acima e, portanto, não parecem necessárias explicações sobre a apropriação desses elementos, para uma re-significação. Mas há um outro detalhe, que ressalta bastante, e que tem de ser discutido: a fantasia de Mickey Mouse, personagem de Walt Disney, com uma reconfiguração que a aproxima do imaginário sadomasoquista. É possível concluir dessa figura, que talvez o discurso em questão sugira que há um caráter sadomasoquista no personagem. Afinal, o fato de ser um rato, animal de laboratório, que passa por inúmeras aventuras para entreter o público, como um bicho experimentado por alguém num cativeiro, é uma explícita situação de dominação, e muitas de suas aventuras, cheias de acidentes e incidentes, podem ser vistas como uma hipnose psicótica sadomasoquista, nas palavras de Walter Benjamin:

“"'Desse modo, os procedimentos da câmara correspondem aos procedimentos graças aos quais a percepção coletiva do público se apropria dos modos de percepção individual do psicótico e do sonhador. $\mathrm{O}$ cinema introduziu uma brecha na velha verdade de Heráclito segundo a qual o mundo dos homens acordados é comum, o dos que dormem é 
privado. E o fez menos pela descrição do mundo onírico que pela criação de personagens do sonho coletivo, como o camundongo Mickey, que hoje percorre o mundo inteiro. Se levarmos em conta as perigosas tensões que a tecnização, com todas as suas consequiências, engendrou nas massas tensões que em estágios críticos assumem um caráter psicótico -, percebemos que essa mesma tecnização abriu a possibilidade de uma imunização contra tais psicoses de massa através de certos filmes, capazes de impedir, pelo desenvolvimento artificial de fantasias sadomasoquistas, seu amadurecimento natural e perigoso... Os filmes grotescos, dos Estados Unidos, e os filmes de Disney, produzem uma explosão terapêutica do inconsciente." (BENJAMIN, 1985: 190)

E por que justamente Mickey? Porque, como o nazismo, ele é uma convenção que erigiu uma existência mitológica, figurativizando o termo complexo entre o homem e o animal. E assim, se utilizando do costumeiro processo de re-elaboração de figuras e temas de discursos da alteridade, Marilyn Manson toma símbolos do nazismo e da Disney para si, de modo a transfigurar elementos de um discurso, cuja ideologia é diferente da sua, em elementos da sua identidade, forjando uma relação contratual virtual ou irônica.

\section{REFERÊNCIAS BIBLIOGRÁFICAS:}

BARROS, D.L.P. de.(1988). Teoria do discurso: fundamentos semióticos. São Paulo, Atual.

BENJAMIN, Walter (1985). Magia e técnica, arte e política. São Paulo, Brasiliense. FIORIN, J. L. (1989). Elementos de análise do discurso. São Paulo,

Contexto/EDUSP.

FLOCH, Jean Marie (1985). Petite mythologie de l'oeil et de l'esprit - pour une sémiotique plastique. Paris-Amsterdã: Hadès-Benjamins (1996). As astúcias da enunciação. São Paulo, Ática.

GREIMAS, A. s.d.. Semântica estrutural. São Paulo, Ática. \& COURTÉS, J. s.d.. Dicionário de semiótica. São Paulo, Ática. e outros (1975). Ensaios de semiótica poética. São Paulo, Cultrix/EDUSP. SITES: http://www.resnet.trinity.edu/ddamon/hierophant/ e http://geocities.yahoo.com.br/thevalleydeath/biomanson.html

\section{Como citar este artigo:}

CANDEIAS, Daniel Levy. Análise semiótica do clip de "This is the new shit "de Marilyn Manson. Estudos Semióticos, Número 2, São Paulo, 2006. Disponível em <www.fflch.usp.br/dl/semiotica/es>. Acesso em "dia/mês/ano". 